\title{
NUEVA INFORMACIÓN SOBRE EL USO DE CERBATANAS EN LAS TIERRAS ALTAS MAYAS
}

\author{
Carlos Navarrete \\ María Elena Ruiz \\ Instituto de Investigaciones Antropológicas, UNAM
}

\section{Introducción}

Nuestro interés por el tema se debe a la circunstancia de haber encontrado cerbatanas en uso durante nuestros recorridos arqueológicosetnográficos en los Altos Cuchumatanes, Guatemala, y en el transcurso del Proyecto Chinkultic en el oriente de Chiapas. Nuestros apuntes se hicieron inicialmente en las temporadas 1975-1976 en este lugar, sitio puerta a la región de los lagos y llanos comitecos. Recibe los caminos que bajan de las serranías guatemaltecas y enlaza sitios de significación regional, como Tenam Rosario, Tenam Puente, Junchavín, otros más lejanos como Santa Elena Poco Uinic, e incluso Toniná, por lo menos en la cercanía de fechas del Clásico Tardío (Navarrete, 1984).

Se trata de un territorio interrelacionado culturalmente desde el Preclásico Superior, con rasgos materiales comunes vigentes hasta el momento de la Conquista. Lingǘrsticamente se manifiestan cuatro lenguas, cuyos límites antiguos en esta parte son todavía inciertos: chuj, tojolabal, coxoh y tzeltal. La información que ofrecemos, recopilada como respaldo a nuestros datos de campo, en algo puede contribuir a animar la discusión sobre un objeto que, en los últimos años, ha destacado gracias a los avances iconográficos de los estudios mayistas.

Por diversos autores conocemos su amplia distribución en el continente americano, siendo uno de los estudios más completos el de Friederici (1911), al que Nordenskiöld (1924) le aumentó datos para Sudamérica (figura 1). Linné (1934) volvió sobre su distribución americana. Schmidt (1913: 1096) y Dixon (1928: 121), en la más pura escuela difusionista, clasificaron el arma como un elemento de la cultura 


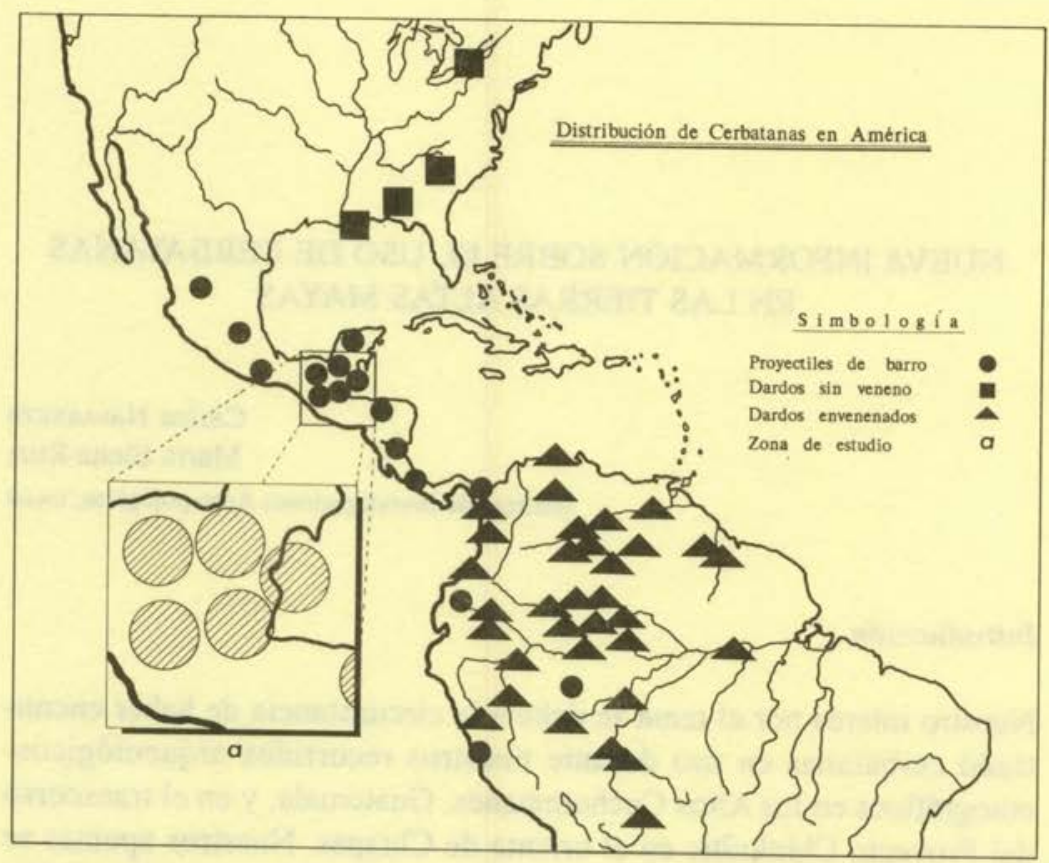

Figura 1. Distribución de las cerbatanas en América, según Nordenskiöld (1924).Se proyecta en un cuadro el área tratada en este artículo

asiática. En general, los estudios realizados sobre su distribución desde el centro de México a Centroamérica, confirman su función práctica de matar animales pequeños $\mathrm{y}$ aves.

Para el norte de México, Bancroft (1875-1876, 2: 411), al tratar de los chichimecas, propone que es una arma propia cuyo uso se generalizó subsecuentemente en otras partes, pero no dio su fuente documental. Friederici (1911: 71) menciona que los jefes de varios "distritos" de Zacatecas usaban esta arma en un juego de caza, lo cual es sugerente por las relaciones que recientes investigaciones han establecido entre el norte de México y la región central de Mesoamérica.

Desafortunadamente, es casi imposible confirmar las evidencias del uso actual en el centro de México, fuera de informes vagos de sobrevivencia en forma de juguetes miniatura. Al tratar, más adelante, la información arqueológica y documental, volveremos a esta región y áreas circundantes. 


\section{Antecedentes etnográficos}

El uso de cerbatanas entre los mayas ha sido documentado etnográficamente desde finales del siglo xIx. Otto Stoll (1986: 204-205) habló brevemente de las cerbatanas "criollas" en el departamento guatemalteco de Retalhuleu.

En la década de los treinta ya se cuenta con nuevos acercamientos, como el realizado por J. Eric Thompson (1930-1988) entre los mayas del sur y centro de la entonces Honduras Británica:

Las cerbatanas usadas por los mayas kekchis del distrito de Toledo varían de longitud entre cuatro y medio a seis pies.

La madera de que se construye es conocida como komoltsê.

Se escoge una parte de la madera y se sumerge bajo el agua en el río, y se deja hasta que la médula suave se pudre. Una plasta de chicle goma sirve como "mirra".

El misil es una pequeña pelotilla de barro cocido que es colocado en la cerbatana con la ayuda de un fragmento de hueso perforado. Algunas veces se emplean semillas duras en lugar de las pelotillas de barro. Las cerbatanas son inútiles para tirar cualquier cosa a excepción de pájaros.

La Farge y Byers (1931: 64-65) las describieron durante su recorrido por las comunidades indígenas de San Miguel y Santa Eulalia, departamento de Huehuetenango. Las vieron como tubos huecos de algunas maderas que crecen en las tierras frías de los alrededores, en donde se encuentra la gente especializada en hacerlas. El arma suele ser 50 centímetros más grande que el propietario. Las más grandes al parecer tuvieron $1.92 \mathrm{~m}$ de largo, un poco más se seis pies. En un extremo del arma se coloca un "pegote", o masa informe de cera que sirve como "mirilla".

Los proyectiles consisten en pelotillas de barro, cuya elaboración se hace a partir de rollos de material crudo del tamaño de la mano, de los cuales se irán elaborando las "balas". En el equipo se incluye una bolsa dividida en dos compartimentos, uno para las pelotillas y el otro para el barro húmedo, pues las municiones deben mantenerse frescas para ser utilizadas de inmediato, cortándolas de un tamaño adecuado y dándoles forma redondeada. Esto se logra haciendo girar la bolita sobre la boca de un casquillo usado de bala de rifle o escopeta, lo que viene a constituir un perfecto ejemplo del concepto "reciclar". En tiempos de Sapper (1903: 53), en esta operación se empleaba un pedazo de hueso de pavo para calibrar el proyectil correctamente. Linné (1934:189) se- 


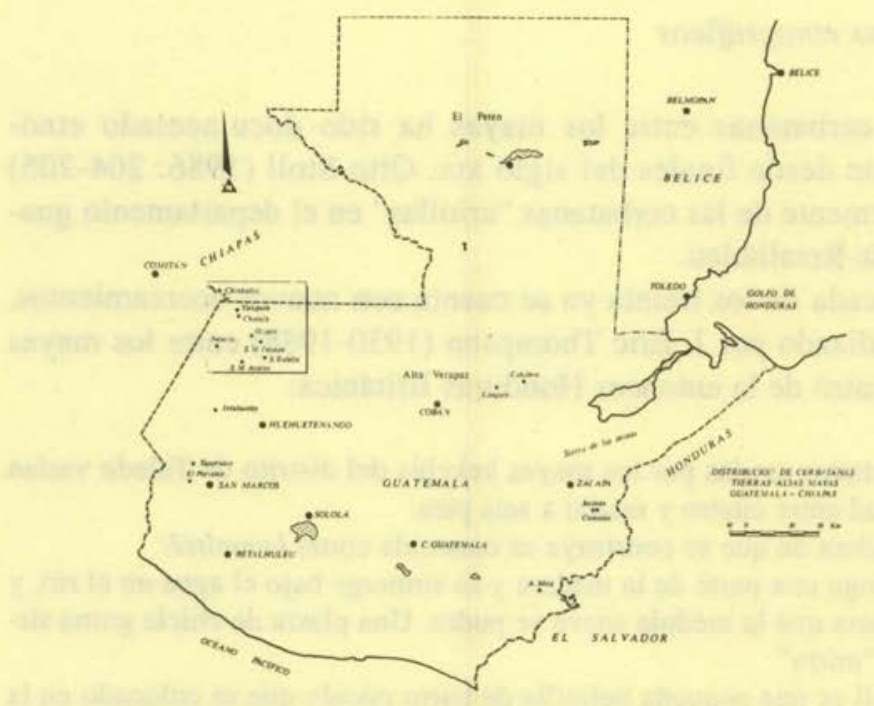

Figura 2. Distribución de las cerbatanas en las tierras altas mayas, con el área de los Cuchumatanes remarcada

ñala que de la bolsa penden o cuelgan dos pedazos de hueso, sirviendo el más largo como "embutidor" o atacador de cañón, como suelen decirle los cazadores; el otro está cortado oblicuamente para dar forma a los proyectiles. Ambos huesos son de mono.

La distribución de las cerbatanas (figura 2), vigente en los años en que Shook (1946: 43) escribió un famoso artículo sobre el tema, abarcaba una extensión territorial que va del quiché, kakchiquel, tzutuhil, ixil, kekchí, chuj, jacalteca y algunos otros al oeste de los mames, en las tierras altas de Chiapas. Shook menciona dos cerbatanas adquiridas en la finca El Porvenir, departamento de San Marcos, entre los años 1942 y 1946, cuya procedencia de factura fue San Ildefonso Ixtahuacán, Huehuetenango. Recientemente, Lee y Clark (1988: 3637) aumentaron dos ejemplares más para la región, comprados bajo pedido a un maestro cerbatanero de la misma zona de las montañas cuchumatanas. La importancia de esta área geográfica como zona productora de cerbatanas se acrecienta con la mención de Chaculá, hecha por Linné (1939: 56-61), uno de los sitios relacionados con las evidencias que ofrecemos.

En nuestro seguimiento contamos con la colaboración de dos informantes, Domingo Lucas Diego y Diego Lucas Domingo, padre e hijo, 
cuyos nombres en español corresponden a la forma de invertir su orden a medida que suceden las generaciones. Vivían entonces (1976) en la aldea Yuxquén perteneciente al municipio de Nentón. Ambos "bajaban" cada año a la zona de Chinkultic en busca de trabajo, y casi siempre llevaban consigo un par de cerbatanas para venderlas o canjearlas al terminar la temporada de siembra, cuando retornaban a Guatemala a laborar en sus tierras (figura 3).

Las plantas de donde cortan el material para fabricar las cerbatanas son el timush y el kapté. Por lo general se aprovechan únicamente dos o tres cañas. Ya en casa y con un alambre calentado al rojo, gastan la parte suave del centro hasta pasarlo al otro extremo y luego alisan el conducto con pedazos de lija jalados con un cordel. Los extremos de la cerbatana se afinan, redondeándoselos y, finalmente, colocan la mira, fijada en una base de cera negra (chagip), en la que incrustan un frijolito rojo (ucún), proveniente de las vainas que produce el árbol llamado colorín. El nombre en lengua chuj de la cerbatana es puup y el de los proyectiles de barro bolok - seguramente un hispanismo de bola-y yolpup (figura 4).

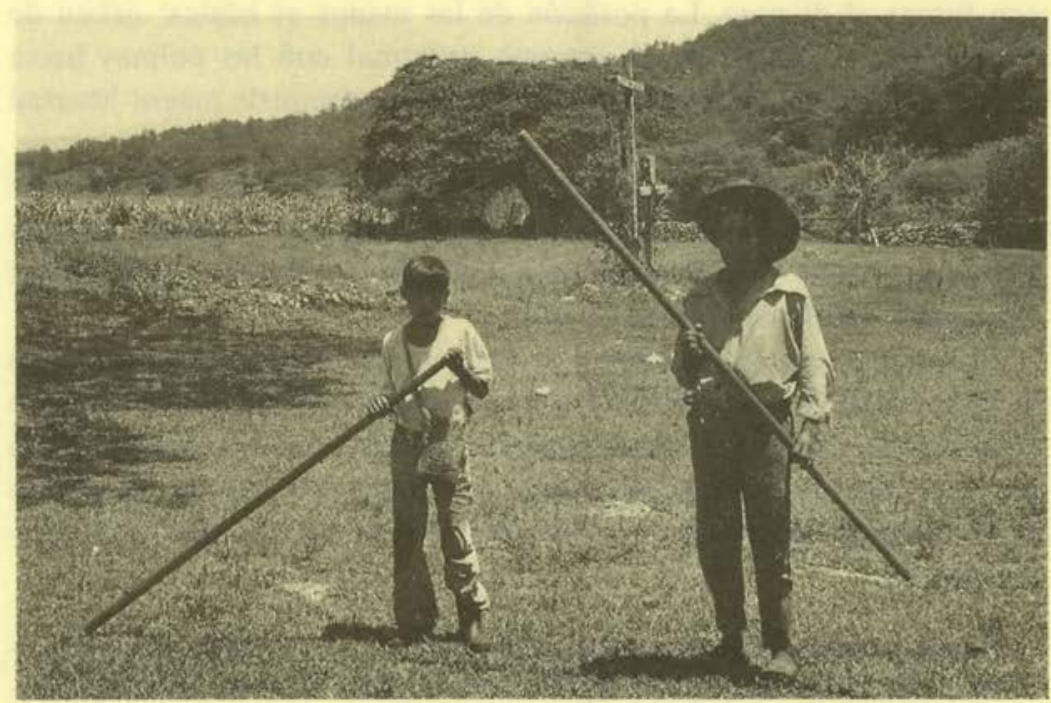

Figura 3. Domingo Lucas Diego e hijo, campesinos guatemaltecos. En la década de los años setenta bajaban de los Chuchumatanes a vender cerbatanas a la región de Chinkultic, Chiapas 


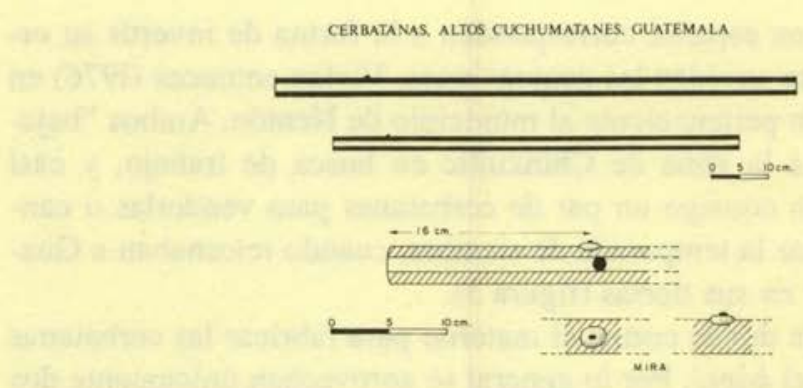

Figura 4. Corte y detalles de las cerbatanas chuchumatanas. Finca Las Palmas, municipio de Nentón, Guatemala

La forma de calibrar los proyectiles es igual a la descrita por La Farge y Byers (1931), por medio de un "cascabillo" o casquillo de bala, de preferencia calibre 38. Esto es reciente; la forma antigua debió haber sido con un hueso como lo describen Sapper y Linné.

Respecto a la manera de efectuar el disparo, nuestros informantes no utilizan ningún tipo de embutidor o atacador, sino que con los labios ligeramente hacia adentro sostienen el proyectil, luego acercan la cerbatana e introducen la bolita con los labios apretados para expeler con fuerza el disparo. La posición de las manos es básica: deben de estar juntas, sosteniendo el extremo proximal con las palmas hacia arriba, para no estorbar la visión de la mira y permitirle mayor libertad al ángulo de tiro (figuras 5 y 6 ).

Esta información la ratificamos regionalmente en las cabeceras de los municipios de Santa Eulalia, San Miguel Acatán y Nentón y en las aldeas de Ocanté y Pacumal del municipio de San Mateo Ixtatán, todas del departamento de Huehuetenango.

Fuera de la región occidental de Guatemala, tenemos el comentario de Dieseldorff (Linné, 1939: 59) sobre su empleo en el departamento de Alta Verapaz. Según las observaciones de Gustavo Espinosa (1940), la presencia del arma se expande hacia el oriente, a la región del trifinio de Guatemala, Honduras y El Salvador, territorio básicamente de filiación chortí:

En esta ocasión hicimos una excursión a la parte alta e intrincada de la Sierra de las Minas. En aquella tupida montaña, llena de lianas, niebla y enormes árboles de edad centenaria, tuve ocasión de ver el uso de una arma antigua, cuyo objeto es cazar pájaros de plumas finas. El señor Artemio Cordón, habitante de estos bosques nos mostró una especie de caña larga, compacta, con un conducto central por donde corren los bodoques de barro 

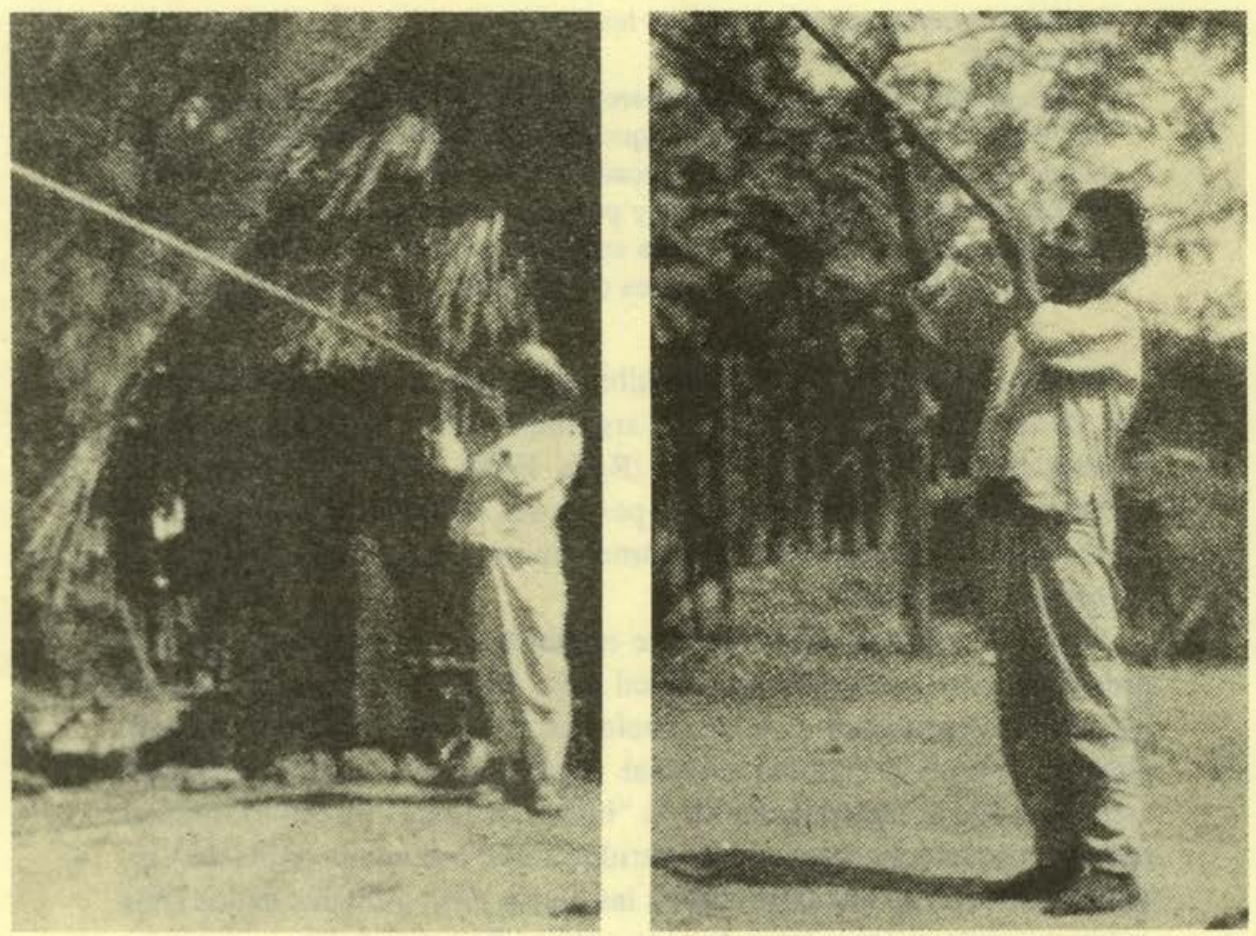

Figura 5. Cerbataneros de Mitla y Ocotlán, Oaxaca, según Linné (1937). Véase la posición de las manos

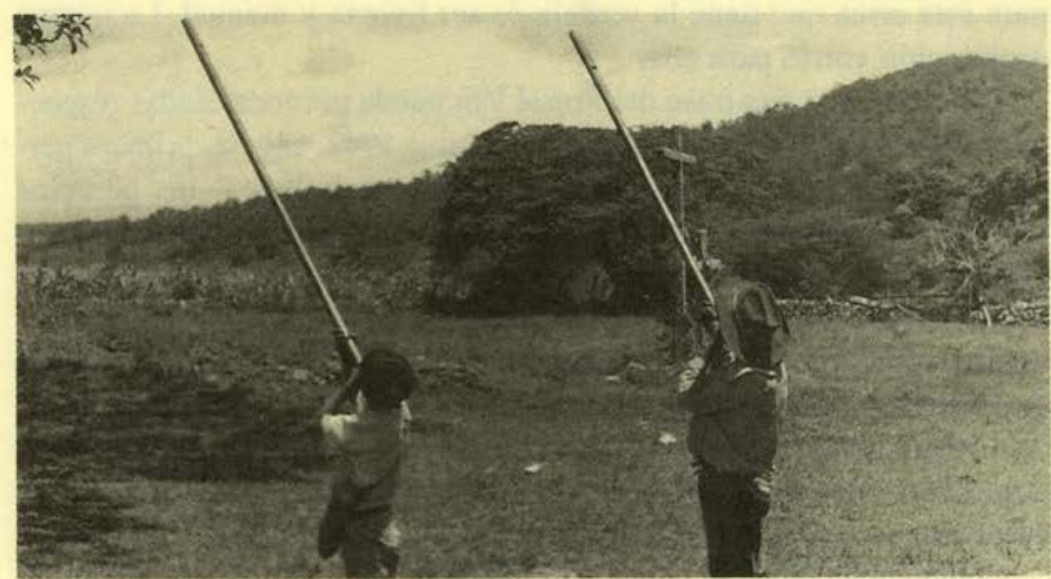

Figura 6. Domingo Lucas Diego y su hijo muestran la posición correcta de las cerbatanas al efectuarse el disparo. En un tiro libre alcanzaron $55 \mathrm{~m}$ de distancia 
hechos pequeñas esferas, a las que les dan forma por medio de un casquillo de bala.

Me cuenta que ya casi ha desaparecido este objeto, sustituido por rifles de viento y municiones de plomo, que tampoco dañan el plumaje y permite que las avecillas puedan ser disecadas. Él las vende a un embalzamador de Zacapa. Anteriormente eran muy populares entre los indios jocotecas y camotecas que botaban monte para sembrar en la sierra. La que traía don Artemio medía un metro con sesenta centímetros y no me la quiso vender.

Dentro de la historia de las prohibiciones del uso de armas aborígenes, de las que existen ordenanzas argumentadas a criterio de las autoridades coloniales y republicanas (Ruiz, 1995: 349-379), también las cerbatanas fueron reglamentadas, pese a ser inofensivas como instrumento bélico. Los ancianos lo resumen en una frase: "antes había más cerbatanas que ahora".

Su prohibición es relativamente reciente, a partir del ascenso a la presidencia de Guatemala del general Jorge Ubico en 1931, con el fin de impedir la mortandad de aves preciosas, principalmente del quetzal, elevado a rango de símbolo nacional. Otra causa que ayudó a desplazar esta arma fue la introducción de la "honda de ligas" (de hule) o resorteras que pronto alcanzaron popularidad sobre todo en la población infantil. Este tipo de honda penetró a las tierras altas a finales de los años veinte, cuando se inventaron los neumáticos de automóviles y aparecieron en el mercado vendedores de huaraches o caites con suela de llanta; también expertos en cortar delgadas tiras y correas de hule, propias para esta arma que tiene la ventaja de ser liviana y manual. La misma prohibición corrió para ella.

Por cierto que una frase del Popol Vuh puede provocar dudas respecto a la antigüiedad de las resorteras (Recinos, 1947, cap. IX, primera parte: 117): "No tenemos nombre contestaron aquellos - los gemelos Hunahpú e Ixbalanque-. No somos más que tiradores con cerbatana y cazadores con liga en los montes". Los campesinos mayas conocen el uso práctico y lo que significa una horqueta de árbol, y si eran capaces de hacer bolas de hule para el juego de pelota, no hubiera sido extraño que también hicieran tiras para ser tensadas. Consideramos que cazar "con liga" debe interpretarse como la acción de atrapar pájaros vivos con alguna sustancia pegajosa untada a las ramas, como lo describe Poch Noguer (s.f.: 299-300) en la Península Ibérica.

Como ha podido observarse, la captura de aves con liga es común en las zonas lacustres, por ejemplo en el Alto Lerma, de donde Albores (1995: 237-238) hace una descripción del método seguido: 
Liga. Alguna aves, como el chicuilote, se cazaban con liga. Esta forma de caza se practicaba en lugares de la ciénega de muy poca profundidad, o sea, menor que la de los lugares donde se ponían los chinchorros [...].

El procedimiento para cazarlos con liga era el siguiente: se conseguía el camote, del cual se sacaba la liga - se molía y se hervía en poquita agua "a modo que quedara como engrudo"- - . Aparte, se adquirían de cien a doscientas varitas de un zacatito muy delgadito "para que no se notara", que midieran de veinte a cincuenta centímetros de largo, pues donde había poca agua y estaba muy bajo se necesitaban varas chicas para que no sobresaliera mucho. Antes de salir de cacería se metían las varitas en el recipiente en el que se había preparado la liga y se llevaban juntas, en montón. Llegando al agua se despegaba una por una, cada varita, y se ensartaban en el fondo de la laguna, a una distancia entre sí de diez a quince centímetros, poniéndose las cien o las doscientas varitas en un mismo lugar. "Para atraer a la parvadita de chicuilotes se ponían unos pájaros de estos mismos disecados, unos cinco o seis o más". Por ejemplo, si el pedazo en que se ensartaban las varitas medía más de tres metros de diámetro, entonces podía ponerse "unos diez chicuilotes disecados". Se colocaban en la mañana, y ya por la tarde, el cazador se escondía atrás de un bordo para cuando apareciera una parvada, "que puede ser de cuarenta, cincuenta o cien chicuilotes, empezara a chiflar lo más parecido al chiflido de las chicuilotas" para que los machos se aproximaran. Al llegar los chicuilotes al lugar en que estaban las varitas con la liga, con sólo rozarlas se les pegaban las plumas de las alas y, al tratar de quitarse el pegamento, éste se adhería aún más. Mediante la técnica de liga, los chicuilotes se agarraban vivos y entretejiéndoseles enseguida las alas, se procedía a colgarlos de un palo.

Después del derrocamiento del presidente Ubico (1944) nuevamente salieron a relucir las cerbatanas y las hondas, a tal grado las segundas que actualmente pueden contarse tantas resorteras por familia como niños varones tenga. Sin embargo, la prohibición de cazar quetzales continuó y se siguió identificando dicha actividad con la posesión de cerbatanas. En las casas las solían guardar entre las varas del tapanco para ocultarlas de los frecuentes cateos practicados por el ejército en busca de guerrilleros. Uno de los lemas populistas de la institución armada es la protección del ave nacional y suele castigarse con dureza al sospechoso de haber cazado alguna.

Contamos una experiencia personal: en el camino Chaculá-San Mateo Ixtatán vimos tirada una pluma de quetzal y el guía indígena aconsejó no tocarla, "porque te moronguean si te la encuentran los soldados". Solamente cuando tienen la seguridad de que no hay elementos armados en la zona salen a cazar con ellas.

Una antigua escena, referente a la esfera práctica y cotidiana del arma como instrumento de caza dedicada a proporcionar alimento, 
ofrece el mapa de Alonso de Santa Cruz o Códice de Uppsala (figura 7), donde se observa a un hombre en plena acción (Linne, 1934: 187).

De acuerdo con los sentimientos y creencias del pueblo mesoamericano, aun en esa actividad tuvo que haber estado presente el ritual religioso al que se obliga todo individuo que penetra en la esfera de la naturaleza. La etnografía actual es reflejo de viejas prácticas, como lo dice el testimonio de Domingo Lucas Diego en los Cuchumatanes:

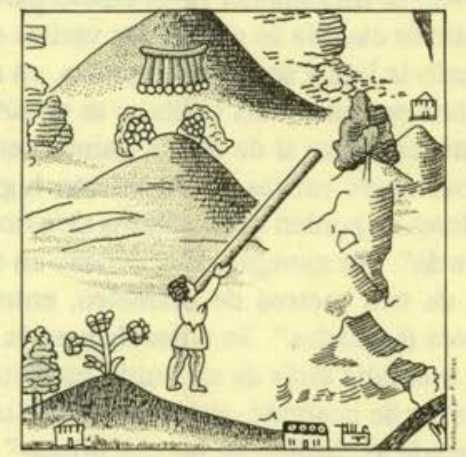

Figura 7. Escena de caza con cerbatana en la cuenca de México. Según el mapa de Alonso de Santa Cruz o Códice de Uppsala, siglo xvı

Cuando ponemos trampas para ardillas y otros animalitos, cuando vamos al monte a cortar o recoger leña, al apuntarle con la escopeta a un venado o a un pato, cuando vamos a tirar algún pajarito bonito con la cerbatana o entramos a un barranco o vamos a quemar monte para sembrar, siempre debemos pedir permiso antes. Siempre estamos obligados a pedirle permiso al Dueño, porque cada lugar que pisamos, cada piedra grande que divisamos, cada río y cada árbol, tiene su Dueño que cuida sus propiedades. Si no querés que haya daño y venga la enfermedad o te desbarranqués, tenés que pedir permiso antes, hacer un rezo y dejar algo, algún regalito en el punto donde vas a entrar. Hay que hacerlo una noche antes, quemar ocote, poner veladora, o adornar la cruz del cerro o echarle trago. Si uno no lo hace se puede perder y hasta rayo llega a caerle.

Del lado chiapaneco, Lee y Clark (1988) ofrecen un importante dato sobre una costumbre directamente relacionada con el acto de cazar:

Es costumbre que al matar algo, una gota de sangre del ave o del animal sea untada al cañón cerca de la mira. Si es pájaro el que ha sido muerto, una plumita fina del pecho será pegada cerca de la mira con la misma gota de sangre. En este último caso, la relación entre la mortal pelotita volátil, el pájaro muerto y la ofrendita de sangre-pluma al cañón y específicamente la mira, es un caso claro de magia imitativa. 
Terminamos la referencia etnográfica con la noticia del actual "baile de micos", danza festiva de la zona quiché de Guatemala, a decir de Rodas (1929: 5). A esta misma representación el abate Brasseur de Bourboug le dio la prestada categoría de "área del cerbatanero" (Vela, 1962: 49).

Ya mencionamos que Linné (1934: 186) encontró en Teotihuacan la presencia de pelotillas y las interpretó como municiones de cerbatana. Posiblemente parte de los proyectiles fechen en el Clásico teotihuacano y otra corresponda a época tardía, probablemente Mazapa. Vaillant (1930 y 1931) halló pelotillas de piedra y de barro al norte de la cuenca de México en Zacatenco y Ticomán; cita a Ottón de Mendizábal y Saville, quienes reportaron el uso de bolas de barro en Oaxaca (Vaillant, 1934: 98). Hay información reciente de este rasgo en contextos teotihuacanos en las excavaciones de Linda Manzanilla (comunicación personal).

Aparte de que algunas son demasiado grandes para caber en la boca del artefacto, tenemos serias dudas para identificarlas como proyectiles si no se tienen otros complementos, sobre todo en el caso de las que aparecen cocidas. En nuestra experiencia etnográfica el retoque terminal se da en el momento previo a utilizárseles para que embonen con exactitud en la boquilla, cosa imposible si están cocidas. En este caso, el término cocido deberá entenderse como "cocidas al sol", es decir endurecidas, sin perder maleabilidad, condición adecuada para recibir el retoque final antes de usarlas.

Sin embargo, la existencia de cerbatanas en el Clásico teotihuacano está probada por un fragmento de tiesto (figura 8), decorado con la figura de un cazador de aves en actitud de disparar, publicado por Lehmann (1933: 73).

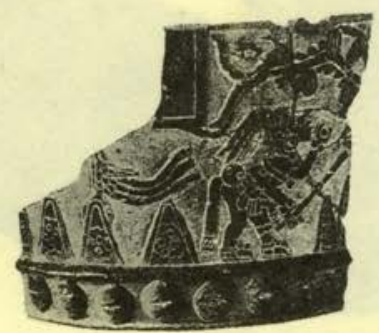

Figura 8. Fragmento de vasija teotihuacana, según Linné (1939). De ser cerbatana el instrumento que sostiene con la mano derecha, en la otra parece llevar el proyectil. La cerbatana puede subir como vara para alcanzar frutos de un árbol, en este caso de cacao 


\section{Arqueología}

Arqueológicamente podríamos pensar que existe información sustancial. Todo lo contrario, las evidencias concretas son reducidas, pues mesoamericanamente sólo hay unas cuantas pelotillas de barro, tanto cocidas como crudas, que se supone pudieran haber servido como proyectiles. Dutton y Hobbs (1943: 62) las identificaron en el material posclásico temprano de Tajumulco, $20 \mathrm{~km}$ al norte de El Porvenir, San Marcos. Lo dedujeron con base en el uso actual de cerbatanas entre los indios mames de la región.

Escena semejante a la del fragmento teotihuacano, aunque más compleja, proporciona el brasero de Palmillas, centro de Veracruz, cuyas figuras moldeadas y aplicadas representan batracios alternados con diseños repetidos de una cacería de pájaros (figura 9).

De la época Clásica, la zona maya aporta los mejores ejemplos, básicamente en la decoración de platos policromados de la fase Tzakol (250-550 d.C.). Son piezas pertenecientes al llamado "arte funerario" por el contexto en que aparecen. Coe (1978), en ese sentido, en la presentación de una esplendida pieza en la que un cerbatanero derriba a un ave de rapiña humanizada (figura10), planteó por primera vez la relación del cazador con los héroes gemelos del Popol Vuh. Siguiendo sus ideas, Rubicsek y Hales (1981: 83-84) comentaron dos vasos más (figuras 11 y 12).

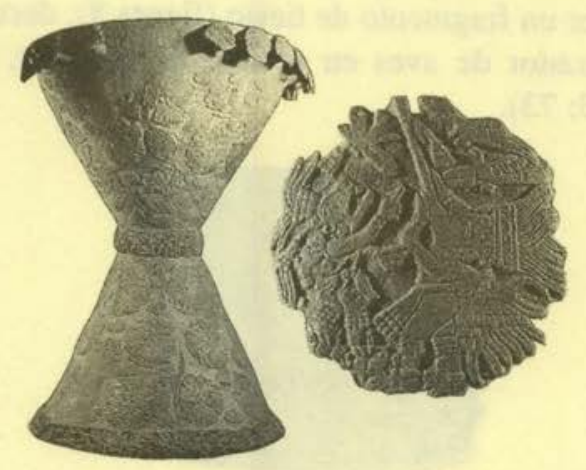

Figura 9. Brasero de palmillas, Veracruz. Las escenas repetidas de un cacería de pajaros alternan con representaciones de batracios. Los pájaros logrados penden de una cuerda que cruza el pecho del personaje animal. Fotografía de

José Luis Rojas, cortesía del Museo Nacional de Antropología, México 


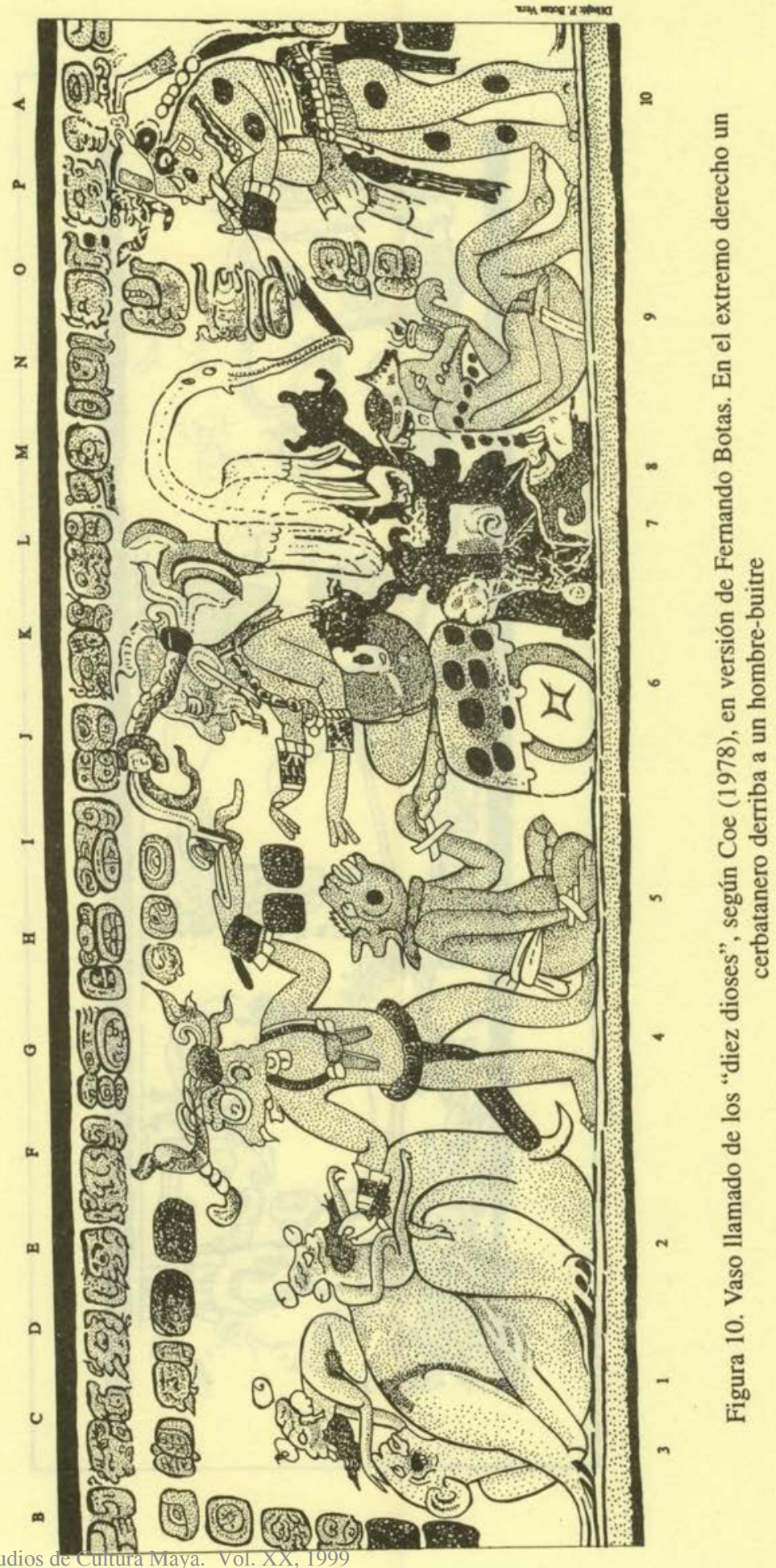

Instituto de Investigaciones Filológicas/

Centro de Estudios Mayas, UNAM 


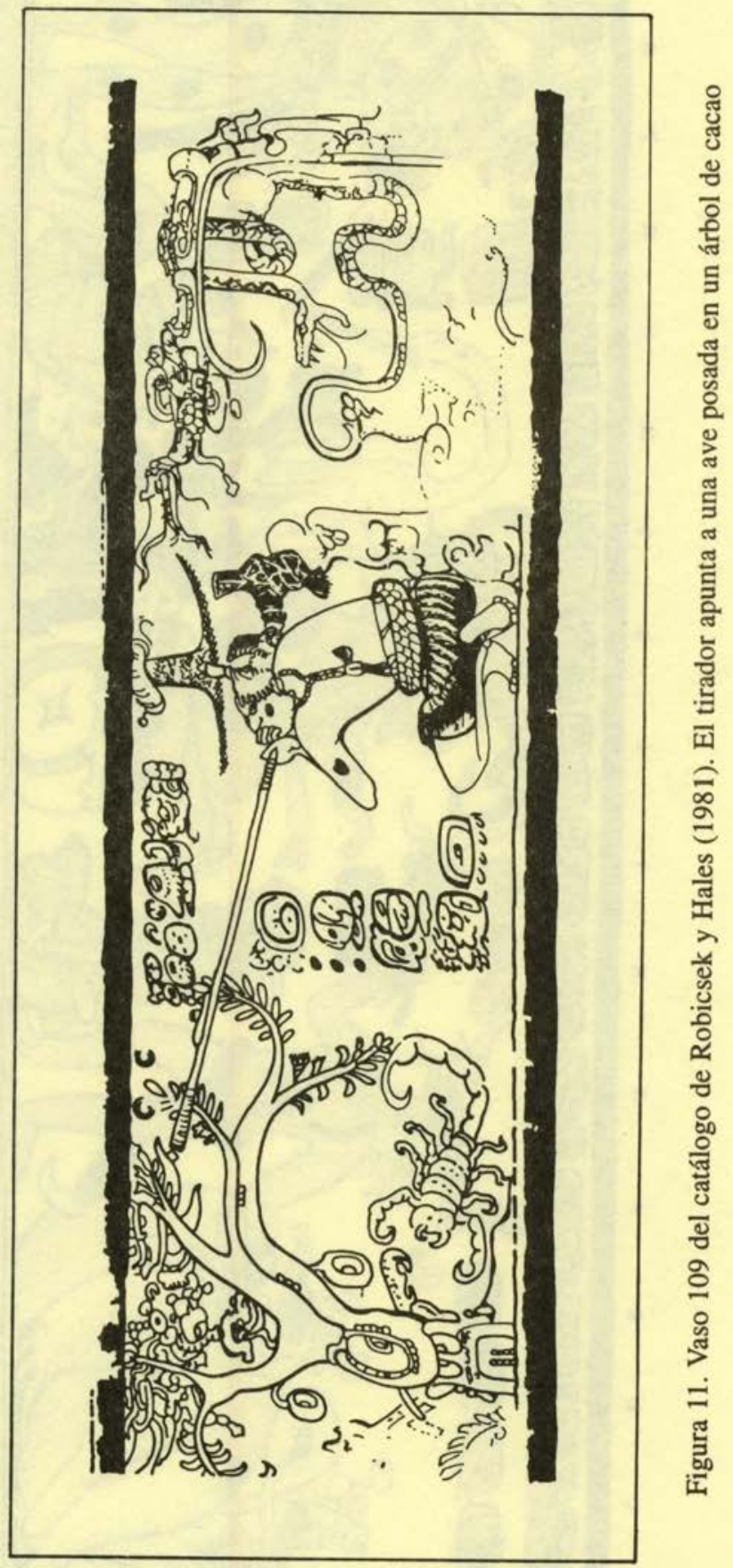




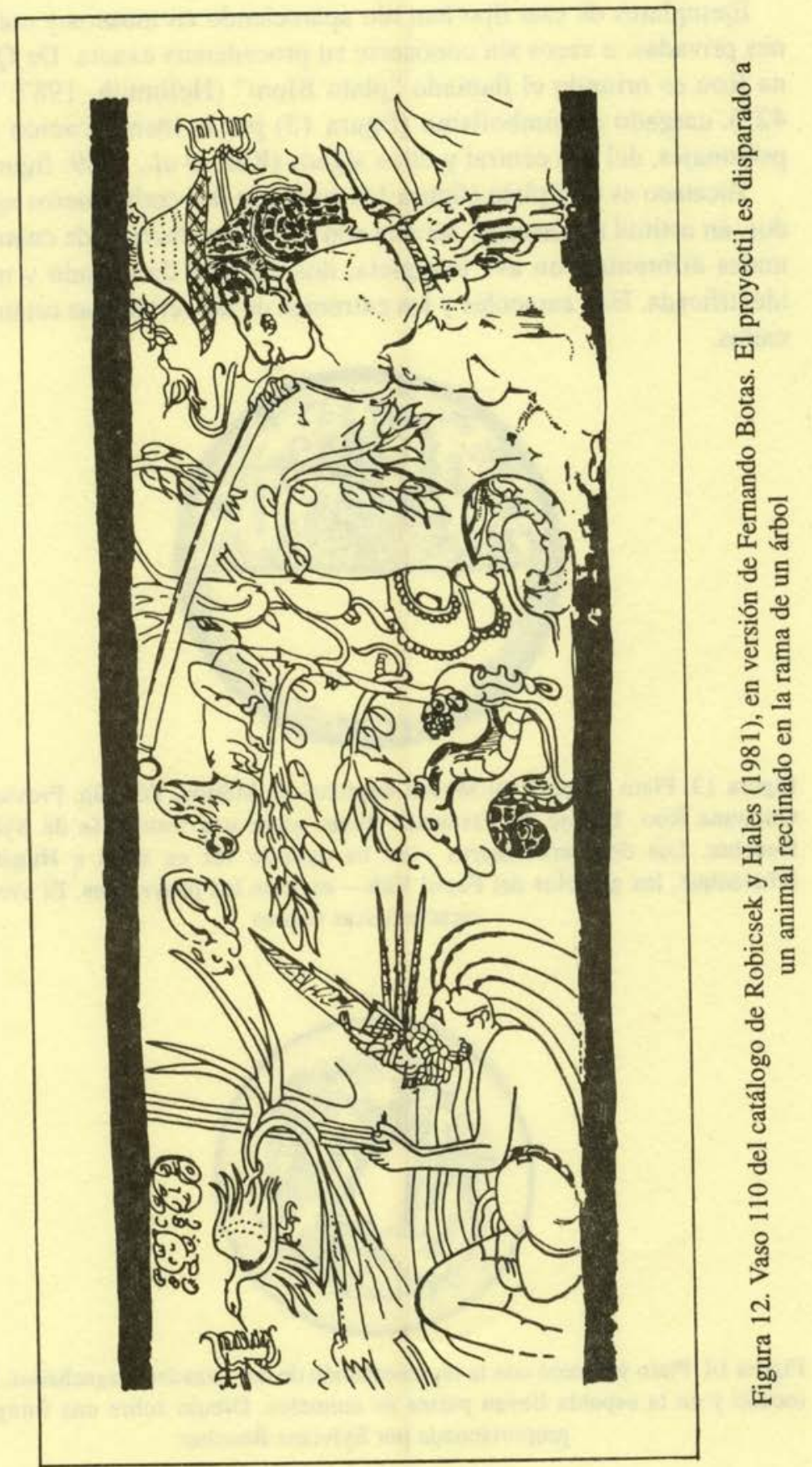


Ejemplares de este tipo han ido apareciendo en museos y colecciones privadas, a veces sin conocerse su procedencia exacta. De Quintana Roo es oriundo el llamado "plato Blom" (Hellmuth, 1987: figura 425), cargado de simbolismo (figura 13) por la identificación de los personajes, del ave central y otros signos (Kerr et al., 1989: figura 12).

Yucateco es otro plato (figura 14) en el que dos cerbataneros agachados, en actitud de cazar, se atavían con cabezas y cuerpos de cuatro animales diferentes: un ave completa, dos cabezas de venado y una no identificada. Hay caracoles y los extremos de las cerbatanas están adornados.

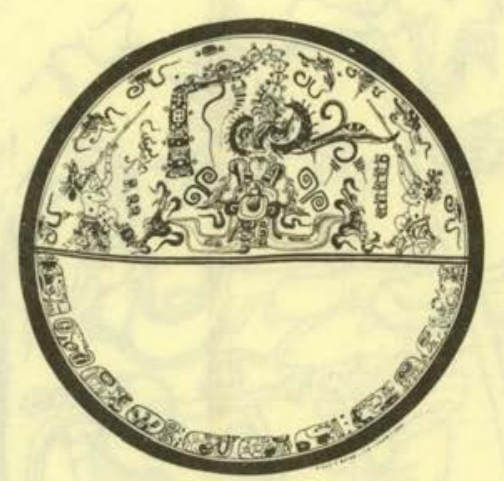

Figura 13. Plato "Blom" del Museo Regional de Mérida, Yucatán. Proviene de Quintana Roo. Dibujo de Fernando Botas sobre una fotografía de Sylviane Boucher. Los dos cerbataneros - se ha querido ver en ellos a Hunahpú e Ixbalanqué, los gemelos del Popol Vuh- expelen los proyectiles. El ave tiene características solares

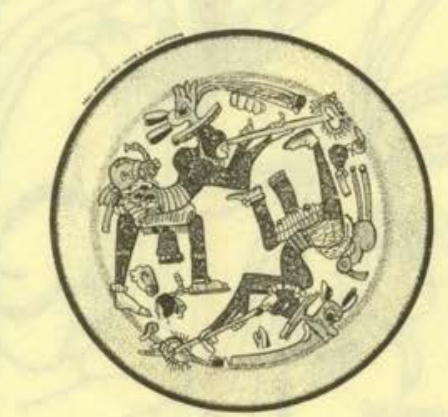

Figura 14. Plato yucateco con la representación de dos cazadores agachados. En el tocado y en la espalda llevan partes de animales. Dibujo sobre una fotografía proporcionada por Sylviane Boucher 


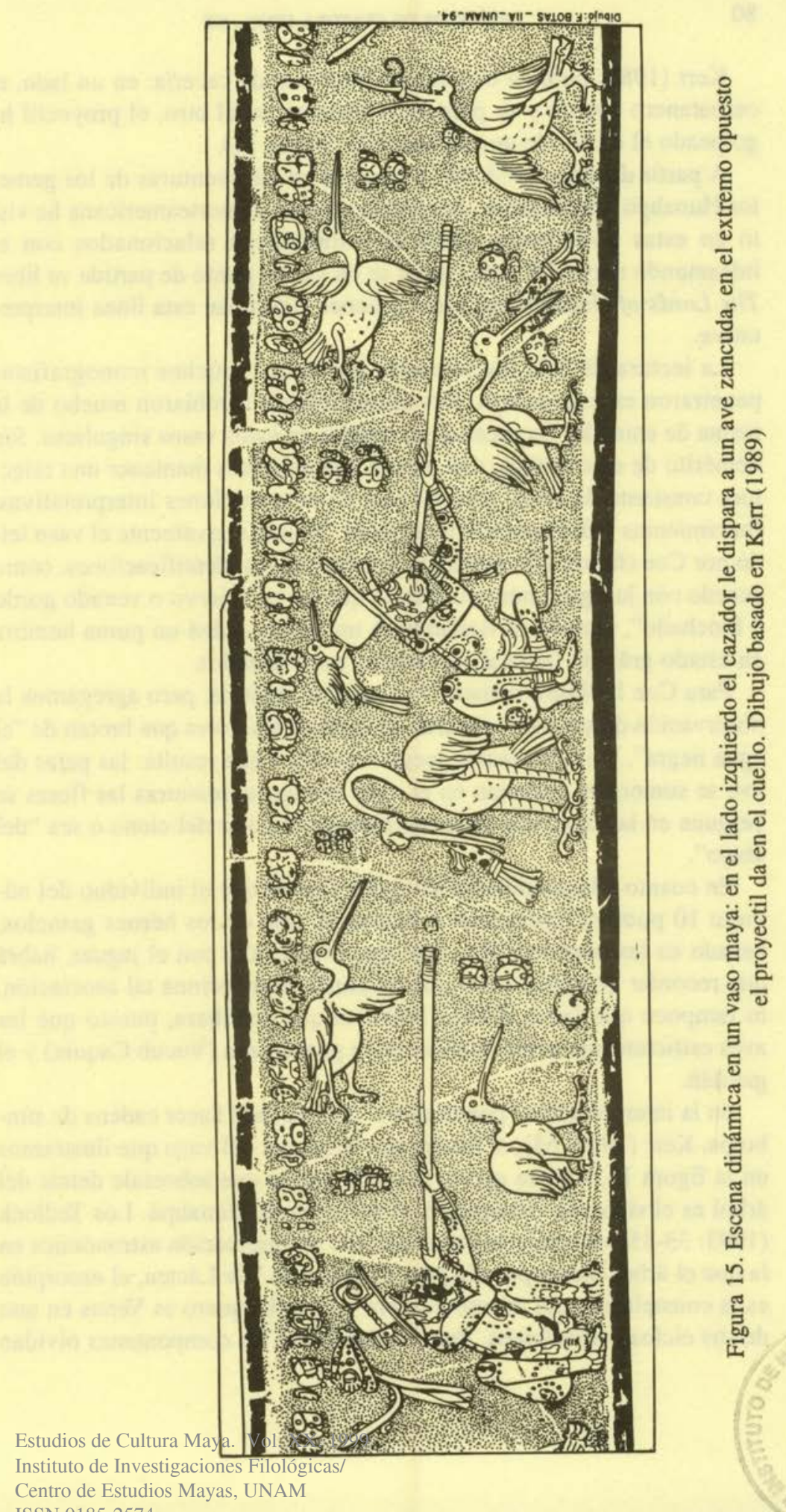


Kerr (1989) publicó una escena dinámica de cacería: en un lado, el cerbatanero apunta y se prepara a disparar; en el otro, el proyectil ha golpeado el cuello de un ave zancuda (figura 15).

A partir de Coe (1978: 58) y basados en las aventuras de los gemelos Hunahpú e Ixbalanque, la escuela epigrafista norteamericana ha visto en estas policromías elementos simbólicos relacionados con el inframundo maya. De aquel autor se ha vuelto punto de partida su libro The Lords of Underworld, entre quienes continúan esta línea interpretativa.

La lectura de Coe fue la puerta por la que muchos iconografistas penetraron en este campo. Sus observaciones cambiaron mucho de la forma de entender las escenas plasmadas en estos vasos singulares. Sin demérito de este avance, nos parece que debemos mantener una relectura constante de ellos, para no caer en exageraciones interpretativas, forzamientos y definiciones mecánicas. Viendo nuevamente el vaso leído por Coe (figura 10), podemos discutir ciertas identificaciones, como sucede con la figura número 3 en la que ve un "ciervo o venado gordo e hinchado", cuando obviamente es un felino, quizá un puma hembra en estado grávido (animal, por cierto, poco tratado).

Para Coe la figura número 7 es un ave acuática, pero agregamos la observación de sus patas oscuras, al igual de las flores que brotan de "el agua negra", y el interesante juego simbólico que resulta: las patas del ave se sumergen, penetran en el agua cenagosa, mientras las flores se yerguen en la superficie trayendo consigo el color del cieno o sea "del abajo".

En cuanto a la posibilidad vista por Coe de que el individuo del número 10 pudiera representar a Hunahpú, uno de los héroes gemelos, basado en las manchas de la piel que lo empatan con el jaguar, habrá que recordar que en el texto quiché jamás se menciona tal asociación, ni tampoco que fuera al Dios buitre al que derribara, puesto que las aves estrictamente mencionadas son la guacamaya (Vucub Caquix) y el gavilán.

En la interpretación "popolvúhica" parece fácil hacer cadena de símbolos. Kerr (1989: 68), al interpretar la escena del vaso que ilustramos en la figura 11, sugiere que la garra de jaguar que sobresale detrás del árbol es el signo de Ixbalanqué, el hermano de Hunahpú. Los Tedlock (1993: 33-35) ven en la misma pieza una representación astronómica en la que el árbol donde posa la guacamaya es la Vía Láctea, el escorpión es la constelación del mismo nombre y el cerbatanero es Venus en uno de sus ciclos calendáricos. Pero al identificar los componentes olvidan 
que el árbol descrito en el Popol Vuh es un nance, y el aquí representado es de cacao, a juzgar por los frutos que brotan del tronco. Igualmente es inadecuado relacionar el árbol con Ixbalanqué y Hunahpú, ya que el "árbol de las calaveras" —una de las cuales embarazó a Ixquic, la madre de los gemelos- es un jícaro o morro.

Insistiremos en el peligro de hilvanar tan "fluidamente" los elementos de la simbología, y más cuando se trata de insertar en los diseños pictóricos de los vasos del periodo Clásico las tradiciones recogidas en un manuscrito de época colonial, en el que se tiende a leer cosas que no dice. En realidad, si recorremos el texto original del Popol Vuh, veremos que la condición de cerbataneros de los hermanos solamente tiene nueve menciones, en cuyo panorama sobresalen hechos como la derrota del vanidoso Vacub Caquix ("7 Guacamaya") a manos de los gemelos, gracias al tiro certero de Hunahpú, que le destrozó la mandíbula y los dientes (capítulo v, primera parte: 107-110). $\mathrm{O}$ en el relato de la trampa que le tienden a Hunbatz y Hunchovén, mientras van tirándole a los numerosos pájaros que cantaban en la copa de un árbol, texto que define el carácter despreocupado de los héroes (capítulo v, segunda parte: 142-144):

...se ocupaban solamente de tirar cerbatana todos los días; no eran amados de la abuela (Ixmucané) ni de Hunbatz, ni de Hunchouén [...] traían sus pájaros cuando venían cada día...

Poseedores de un sentido casi picaresco de la vida - se resalta continuamente en el relato-, el arma es herramienta de diversión y con ella soslayan los compromisos cotidianos, hasta olvidarse de cosas esenciales como sembrar la milpa de la abuela (capítulo VI, segunda parte: 147-148):

Enseguida tomaron sus hachas, sus piochas y sus azadas de palo y se fueron llevando cada uno su cerbatana al hombro [...].

Enseguida se pusiron a tirar con la cerbatana; ciertamente no hacían ningún trabajo de labranza...

En cada acción que los gemelos emprenden queda manifiesta su destreza en el uso del arma. Por ejemplo, al recibir la visita del gavilán mensajero de los Señores de Xibalbá (capítulo vII, segunda parte: 155):

¿Quién está gritando? ¡Vengan nuestras cerbatanas!, exclamaron. Y disparándole enseguda al gavilán, le dirigieron el bodoque a la niña del ojo, y dando vuelta se vino al suelo. 
Durante el viaje de los hermanos al inframundo, al resolver uno de los peligros a que se ven sujetos, le dan a las cerbatanas un uso diferente, típico en la esfera del mito (capítulo vIII, segunda parte: 157):

Pasaron también por un río de podre y por un río de sangre, donde debían de ser destruidos según pensaban los de Xibalbá; pero no los tocaron con sus pies, sino que los atravesaron sobre sus cerbatanas.

Otra manifestación fantástica ocurre en la prueba a que los someten en Xibalbá de pasar una noche en la casa de los murciélagos (capítulo $\mathrm{X}$, segunda parte: 168-169). Para protegerse duermen dentro del conducto de sus armas y Hunahpú, ansioso por ver si amaneció, saca la cabeza afuera de la boca de la cerbatana y es decapitado.

Igualmente mágica es la acción de matar pájaros sin proyectil durante la pugna con Cabracán, señor de los temblores y terremotos, al que conducen a la montaña donde nace el sol (capítulo IX, primera parte: 118).

Tenemos que llevarte enmedio de nosotros: uno irá a tu mano izquierda y otro a tu mano derecha, porque tenemos nuestras cerbatanas, $y$ si hubiere pájaros les tiraremos.

$\mathrm{Y}$ así iban alegres, probando sus cerbatanas: pero cuando tiraban con ellas, no usaban bodoque de barro en el tubo de sus cerbatanas, sino que sólo con el soplo derribaban a los pájaros cuando les tiraban, de lo cual se admiraba grandemente Cabracán.

La relación de los cerros con el nacimiento del sol está presente en la tradición oral contemporánea de los chujes de San Mateo Ixtatán. En sus mitos de creación mencionan al "primer cerbatanero", quien caminó nueve días siguiendo el vuelo de un quetzal hasta alcanzarlo y derribarlo en el cerro Jolomcú, cuya traducción a lengua kanjoval significa "cabeza de sol", que alude al punto de salida del astro (Navarrete, 1980).

En la parafernalia de las relaciones sociales hay que consignar el uso del arma como parte de los objetos que conforman los símbolos del poder. En las expresiones del arte maya aquí presentadas, los tiradores están en manos de personajes destacados, de jerarquía elevada, y habría que agregar el contexto arqueológico de élite en que aparecen (figuras 16 y 17).

Hay una pequeña escultura modelada en barro, procedente del Quiché, dada a conocer por Favrot Peterson (1990: 100-101, figura 69). Representa a un hombre joven (figura 18 ), con el pecho adornado con 

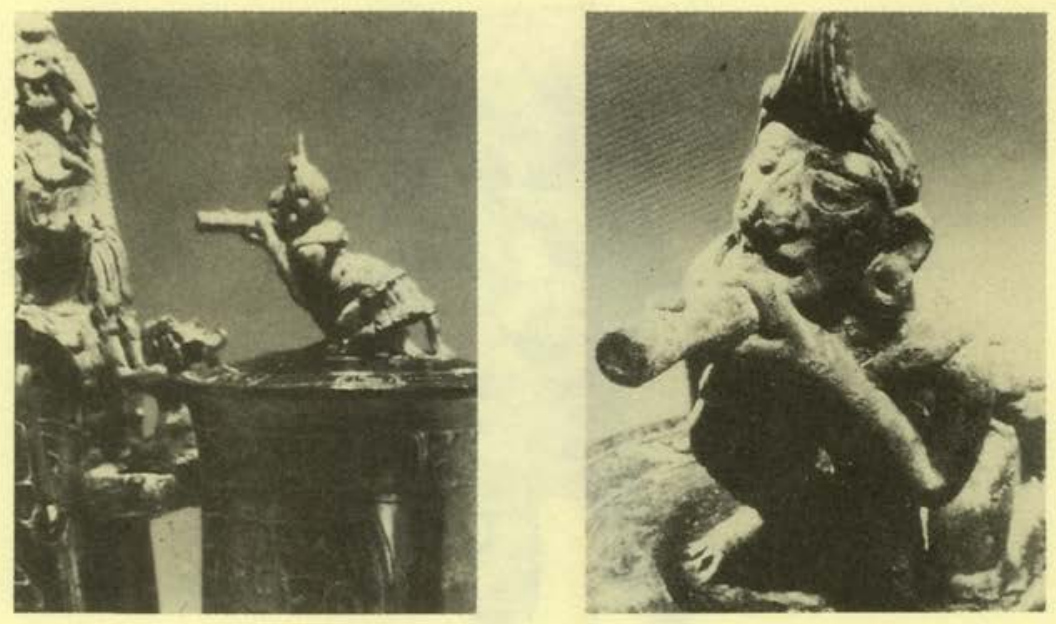

Figura 16. Doble vaso cilíndrico del Clásico Temprano maya, procedente de Río Azul, departamento del Petén, Guatemala. Según Kerr (1989) y de acuerdo con el relato del Popol Vuh, las figuras de la parte superior podrían representar a Hunahpú disparándole a Vacub-Caquix; el personaje situado en el puente que une las vasijas sería el representante de Ixbalanqué

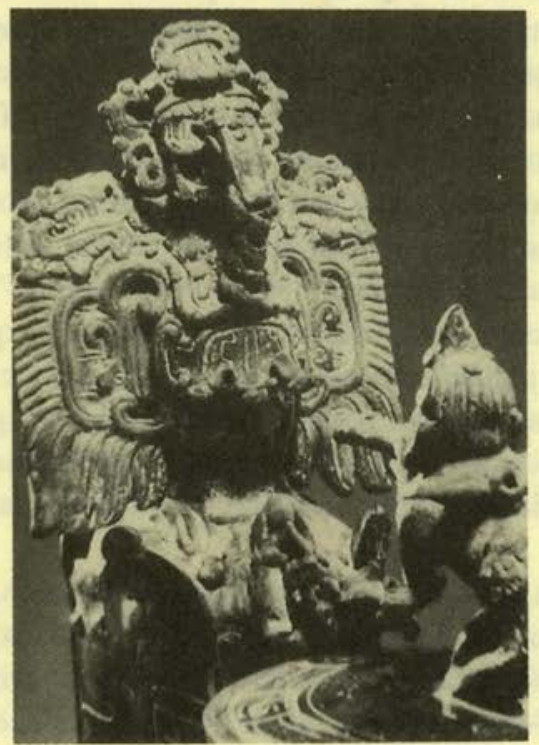

Figura 17. Detalle con el personaje disparándole a Vacub-Caquix, según la interpretación de Kerr, et al. 


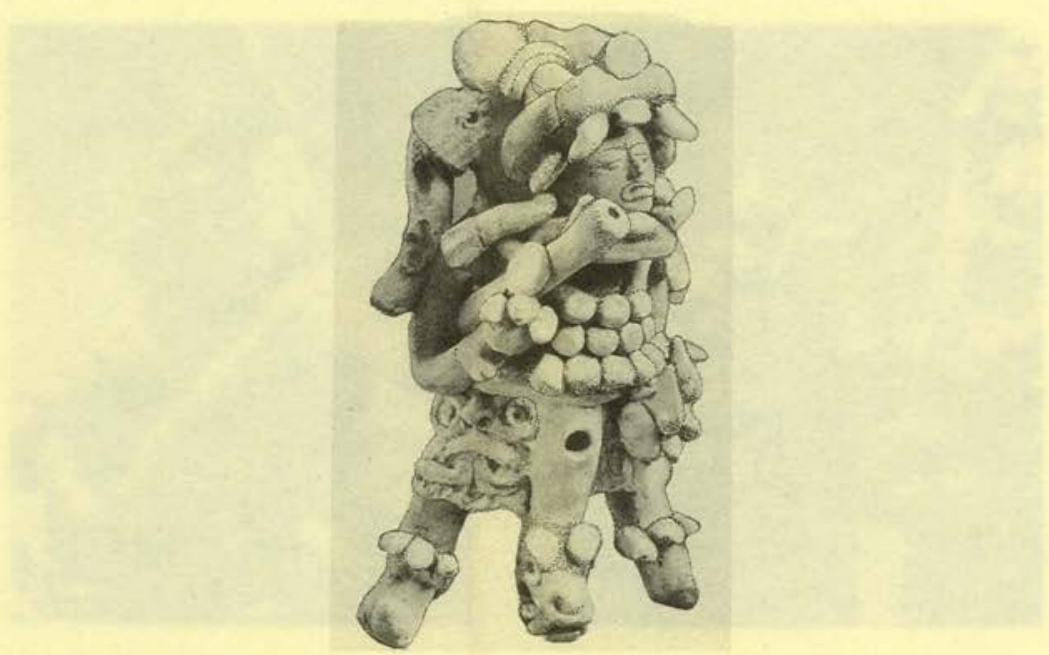

Figura 18. Escultura en barro de un personaje de gran atuendo con el arma bajo el brazo derecho, según Favrot Peterson (1990: figura 69), quien "popolvuhianamente" lo identifica con Ixbalanqué, uno de los héroes gemelos

un grueso collar de tres hiladas y sus extremidades lucen pulseras y ajorcas; el yelmo es de jaguar, de él penden unos apéndices con las manchas de animal en forma de flores. Abajo se cubre con una especie de faldellín del que cuelgan dos pesas; en el otro lado va un mascarón azul con la lengua bífida roja y los ojos abiertos en círculo. El taparrabo guarda un alto contenido fálico por tratarse de la representación de una serpiente. Bajo el brazo y con la mano derecha sostiene una cerbatana color azul con embocadura al frente. Según la ficha del catálogo de Favrot Peterson, y de nuevo en la explicación "popolvúhica", el personaje representa a uno de los héroes gemelos, quizá Ixbalanqué, "el pequeño sol jaguar". Su condición de cazador "elegante" la da el rico atuendo, el arma y los pájaros muertos que cuelgan de la cintura. Se conjugan aspectos que concurren en el ceremonial de la caza: sol jaguar, un posible mascarón acuático y la fecundidad-tierra señalada por la serpiente.

Fuera del área contamos con información dispersa. Por ejemplo, en la región mixteca, al referirse al posclásico Códice Bodley (figura 19), Burland (1949: 101-102) comenta que, desafortunadamente, en la investigación de los códices mixtecos se ha hecho hincapié en las genealogías y geonimias, pero se ha dejado de lado el aspecto ceremonial que contienen algunas escenas, como ocurre con el cerbatanero de la página 38 , 


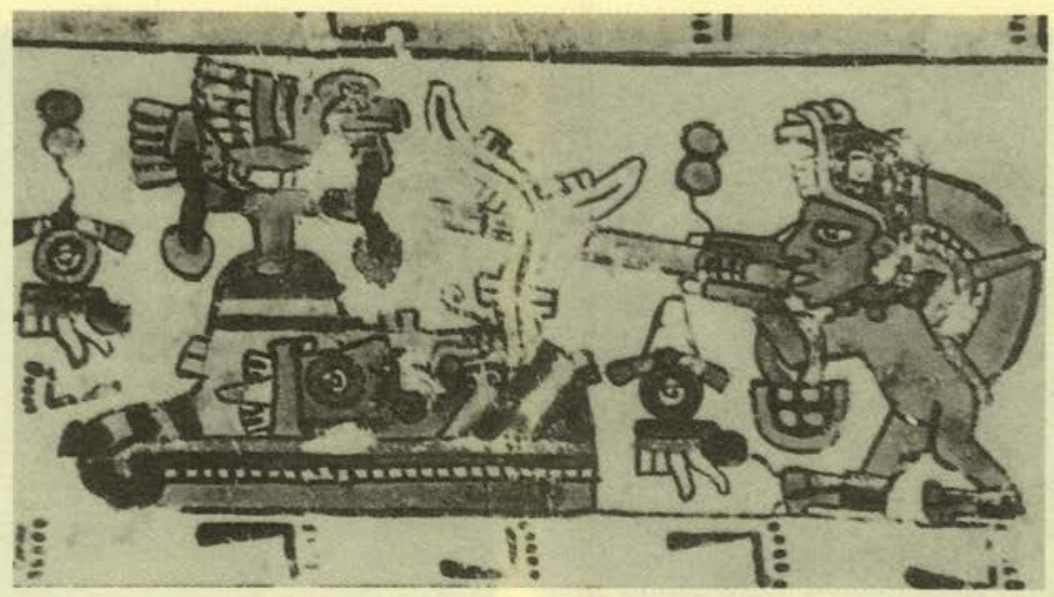

Figura 19. Cerbatanero con escudo solar y yelmo de serpiente, en actitud de tirarle a un pájaro posado en un árbol, arriba de un glifo de lugar "cerro". Página 38, tercera faja, del Códice Bodley 2858, de acuerdo con Caso (1960)

al que Alfonso Caso (1960: 54) no aludió, ni tampoco lo hizo José Corona Núñez (1964: 72-73). La pintura muestra un individuo con yelmo de cabeza de conejo y un disco solar en la espalda; la cerbatana apunta a un pájaro posado sobre un árbol de cuatro ramas, situado en la punta de un cerro-agua, como indica el rostro de Tláloc acostado en el interior. Una planta de maíz completa el jeroglífico.

En el brasero de Palmillas, centro de Veracruz, alternan aplicaciones moldeadas de barro con figuras de batracios y la escena repetida de una cacería de pájaros. Un personaje zoomorfo, quizá un cándido (¿nahual?), señala el árbol, mientras otro, seguramente un jerarca, dispara hacia arriba. De una cuerda que cruza el pecho del primero penden las piezas logradas (figuras 9,20 y 21). Escenas de esta naturaleza podrían haber tenido también un carácter laico, en el ámbito de la nobleza que se regalaba ratos de esparcimiento. Si esta pieza arqueológica hubiera aparecido en el área maya, los iconografistas de la escuela norteamericana seguramente le habrían encontrado una explicación aplicándole mitos quichés.

Para los aztecas el arma debió tener un papel importante. Véase la segunda carta de Cortés al emperador Carlos V, ya citada al respecto por Linné (1934: 187), donde el conquistador se refiere al presente enviado por Moctezuma al soberano, incluidas 12 cerbatanas y una bolsa para los proyectiles (Cortés, 1969: 50): 

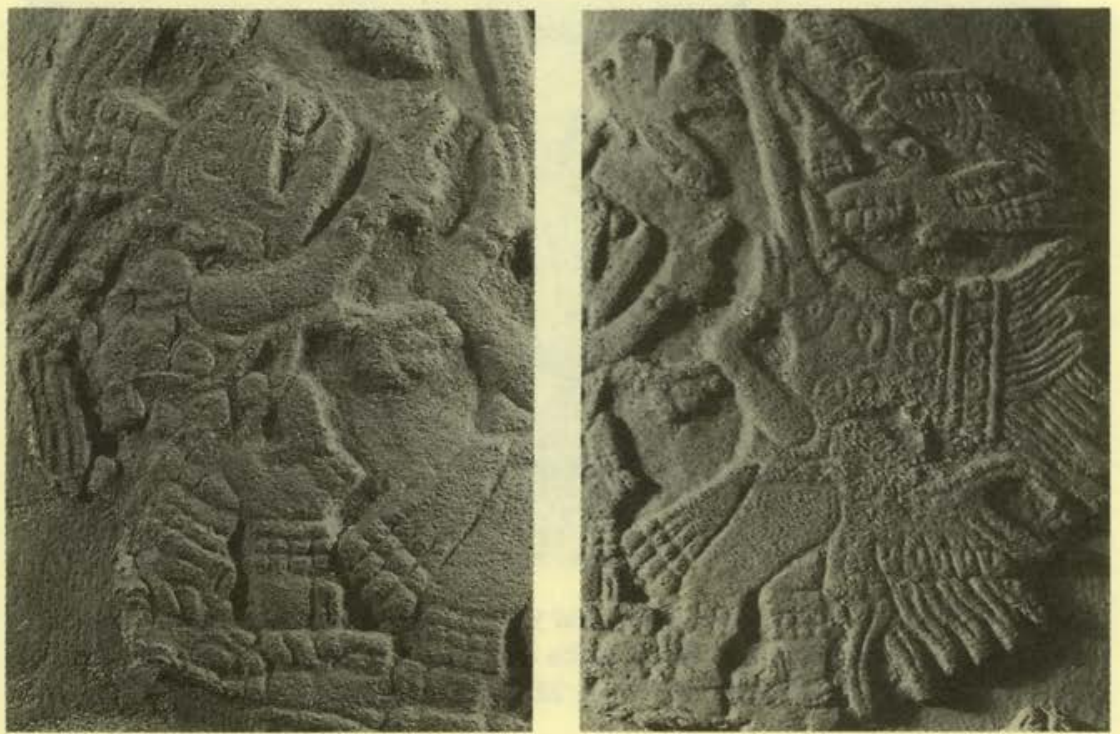

Figura 20. Acercamiento a la escena de cacería del brasero de Palmillas: $a$ ) el hombre-animal (?) señala los pájaros y carga las piezas logradas; $b$ ) un individuo de jerarquía elevada, de acuerdo con la elegancia del atuendo, en actitud de disparar.

Fotografías José Luis Rojas, cortesía MNA. INAH

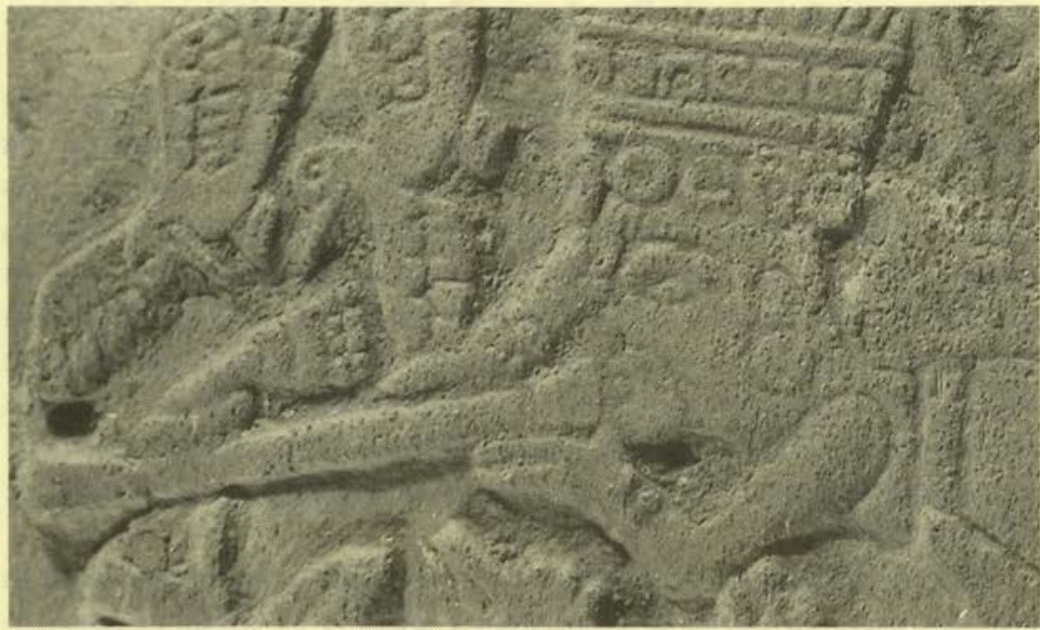

Figura 21. Detalle del cazador de Palmillas. Nótense los labios hacia adelante y la posición de las manos para sostener el arma, semejante a los ejemplos etnográficos contemporáneos. Fotografía José Luis Rojas, MNA. INAH 
También me dió una docena de cerbatanas de las con que el tiraba, que tampoco no sabré decir a vuestra alteza su perfección, porque eran todas pintadas de muy excelentes pinturas y perfectos matices, en que había figuradas muchas maneras de avecicas y animales y árboles y flores y otras diversas cosas, y tenían los brocales y puntería tan grandes como un geme de oro, y en el medio otro tanto muy labrado. Dióme para con ellas un carniel de red de oro para los bodoques, que también me dijo que me había de dar de oro, y dióme unas turquesas de oro y otras muchas cosas, cuyo número es casi infinito.

Bernal Díaz del Castillo (1944: 410-411) fue otro testigo del presente real, pero el número de cerbatanas que da es de tres. Dice que Moctezuma ordenó que fuera llevado directamente a Cortés:

...también le quiero enviar tres cervatanas con sus esqueros y bodoqueras, y que tienen tales obras de pedrería, que se holgará de verlas [...]. Pues las tres cervatanas con sus bodoqueras, los engastes que tenían de pedrerías y perlas y las pinturas de pluma y de pajaritos llenos de aljófar y otras aves, todo era de gran valor.

Cuando el cronista dice "bodoqueras", ¿no se estará refiriendo a moldes para municiones? De ser afirmativo, constituiría un dato importante por la posibilidad de obtener algún tipo de medida prehispánica.

Según cita de Linné (1934), Oviedo concuerda con Cortés en el número de piezas:

También dió Moctezuma á Cortés una docena de cerbatanas de las con quél tiraba, muy hermosas, porque eran todas pintadas de muy excelentes pinturas é perfettos matices, en que avia figuradas muchas é diferenciadas maneras de avecicas é animales é árboles é flores é otras diverssas cosas é fantasias.

Según Friederici, las cerbatanas como el resto de los presentes nunca llegaron a su destino, dado que el barco fue capturado por piratas, perdiéndose así una singular muestra de lo que serían las cerbatanas de lujo.

El acto de ofrendar o regalar tiene que verse como parte de un antiguo ceremonial, y seguramente en el protocolo entre gobernantes cada objeto guardaba algún significado: eran cosas de señores para señores; y en eso entraban las preciosas cerbatanas que el tlatoani de México enviara al emperador de España. De la educación y adiestramiento de dos personajes habla el Popol Vuh (capítulo I, primera parte: 122): 
...eran grandes sabios y grande era su sabiduría; eran adivinos aquí en la tierra, de buena índole y buenas costumbres. Todas las artes les fueron enseñadas a Humbatz y Hunchouén, los hijos de Hun-Hunahpú.

Eran flautistas, cantores, tiradores con cerbatana, pintores, escultores, joyeros, plateros: esto eran Humbatz y Hunchouén.

\section{Recapitulación}

La presencia de las cerbatanas en el Nuevo Mundo muestra dos tipos de arma: con fines bélicos una, funcional para lanzar dardos y de distribución sudamericana; la otra lanza proyectiles esféricos de barro crudo para cazar fauna menor, principalmente pájaros, y se concentra en Mesoamérica y en el norte.

Su función social es diversa. Servía para conseguir carne y ciertos huesos, y obtener plumas para usos domésticos y artesanales, y en el caso de las finas y vistosas, para intercambio comercial de camino largo o trueque cercano. Entre los tributos que consigna el Códice Mendocino, la región del Soconusco enviaba a Moctezuma manojos de plumas y pieles desolladas de pájaros de colores, y es de pensar que para conseguirlas fueron básicas las cerbatanas. Como puede verse en el Apéndice final, en plena Colonia (1674) continuaba el comercio de plumas entre la Verapaz y la Mixteca.

La cerbatana es un arma asociada a varios de los héroes míticos del Popol Vuh, y algunos autores las ven representadas gráficamente en el arte de la alfarería maya de época clásica y su complicada trama simbólica. Uno o dos personajes disparan con cerbatanas al ave guacamaya-sol, a un hombre buitre, y a pájaros que posan en árboles, a veces de cacao, o en árboles glifos, y hay una relación entre los hechos del relato pictórico y el ámbito cosmogónico del inframundo.

En el uso de las cerbatanas se manifiestan dos categorías sociales: están los instrumentos de uso diario, sencillos, despojados de adornos, que usaban los campesinos de la región lacustre de México, como lo muestra el mapa de Alonso de Santa Cruz, y las que enviara Moctezuma a Cortés como presente real junto con otras piezas maravillosas. Cerbatanas para vivir y cerbatanas para mandar.

El empleo del arma ha decrecido en Mesoamérica a partir de los años cuarenta, con la introducción de rifles de viento y balines, que tampoco dañan las pieles y las plumas. Sobrevive en regiones aisladas de las tierras altas mayas. 


\section{APÉNDICE}

Testamento del Alferez Agustín de Torres Ves ${ }^{\circ}$. de la Ciudad de Santiago de Guatemala, natural de Xerez de la Frontera, Reino de Andalucía. 1674.

Ytem declaro que a Joan Pérez Manarro le di para que llevase por mi cuenta al Reino de la Nueba España una cantidad de rosarios que fueron cinquenta y tres dosenas, las treinta y tres de coyol y las veinte labradas de boquillas y veinte y cuatro manoxos de veinte plumas cada uno de la Verapaz chicas para que por mi cuenta lo venda y de su prosedido me traiga unas guarniciones y cuerdas y otras menudencias $=\mathrm{Y}$ así mismo llebe orden mia para que el dho. Joan Pérez Manarro de en la Misteca las dhas plumas a Bernardo Orti Vez ${ }^{\circ}$ della para que las venda y emplee su prosedido en unos guaipiles adamascados $=\mathrm{y}$ los dhos. rosarios y plumas me tienen de primer costo trecientos pesos poco mas o menos declaro para que conste.

(Archivo General de Centro America: exp. A, 120, leg. 1030, fol. 275v-276)

\section{Bibliografía}

\section{Albores Zárate, A. Beatriz}

1995 Tules y sirenas. El impacto ecológico y cultural de la industrialización del Alto Lerma, El Colegio Mexiquense A. C., Gobierno del Edo. de México, Secretaría de Ecología, México.

BANCROFT, Hubert Howe

1875-1876 The Native Races of the Pacific States of Nor America, vol. 2, Londres.

Burland, C. A.

1949 "The Blow-gun in pre-Spanish Mexico", en Ethnos, vol. 14: 2-4, The Ethnographical Museum of Sweden, Estocolmo.

CAso, Alfonso

1960 Interpretación del Códice Bodley 2858, Sociedad Mexicana de Antropología, México.

COE, Michael D.

1978 Lords of the Underworld. Master-pieces of Classic Maya Ceramics, The Art Museum, Princeton University Press, Nueva Jersey.

Corona NúNez, José

1964 "Códice Bodley", en Antigüedades de México, vol. II, Secretaría de Hacienda y Crédito Público, México. 
CoRTÉs, Hernán

1969 Cartas de Relación, Editorial Porrúa, México,

Díaz del CAstillo, Bernal

1944 Historia verdadera de la Conquista de la Nueva España, introducción y notas de Joaquín Ramírez Cabañas, tomo I, Pedro Robredo, México.

Dixon, Roland B.

1928 The Building of Cultures, Nueva York, Londres.

Dutron, Bertha P. Hilda R. HobBs.

1943 Excavations at Tajumulco, Guatemala, Monographs of the School of America Research 9, Santa Fe, Nuevo México.

EsPINosa, Gustavo

1940 "Viaje a Asunción Mita. Joya del Oriente", en suplemento de $\mathrm{Fe}$ ria de noviembre, Publicaciones del Ministerio de Fomento, Guatemala.

FAVRot Peterson, Jeanette

1990 Precolumbian Flora and Fauna. Continuity of plant and animal themes in Mesoamerica Art, A Mingei International Museum Exhibition, Documentary Publication, San Diego, California.

FRIEDERICI, Georg

1911 "Die geographische Verbreitung des Blasrohrs in America", en Petermanns Geographischen, Mitteilungen.

Hellmuth, M. Nicholas

1987 Monster und Menschen (Monster and Men in Maya Art). In der Maya-Kunst, eine Ikonographie der alten Religionen Mexikos und Guatemalas, Akademische Druck-u, Verlagsantalt, Graz.

Kerr, Justin, Michael D. Coe, Mary Ellen Miller, Linda Schele y David StUART

1989 The Maya Vase Book. A corpus of rollout photographs of Mayas vases, vol. 1, Nueva York.

LA FARge H., Olivier, Douglas BYers

1931 The Year Bearer's People, Publication núm. 8, Tulane University of Lusiana, Nueva Orleans.

LeE, Thomas; John, E. ClarK

1988 "Oro, tela y xute: investigaciones arqueológicas en la región Camcum, Colonia Las Delicias, Chiapas", en Arqueología, núm. 4, Dirección de Monumentos Prehispánicos, INAH, México.

LeHMANN, Walter

1933 Aus den Pyramidentstädten in Alt-Mexico, Berlín. 
LiNNÉ, S.

1934 "The Geographical Distribution of the Blowgun in America", Apendix 5, en Archaeological Research at Teotihuacan, New Series, Publication 1, The Etnographical Museum of Sweden, Estocolmo.

1937 "Hunting and Fishing in the Valley of Mexico in the Middle of the $16^{\text {th }}$ Century", en Ethnos, vol. 2, núm. 2, The Ethnographical Museum of Sweden, Estocolmo.

1939 "Blow-Guns in Ancient Mexico", en Ethnos, núm. 2, Bokförlags Aktiebolaget Thule, Suecia, Estocolmo.

NAVARRETE, Carlos

1980 Diario de campo de los Cuchumatanes, núm. 2, manuscrito.

1984 Guía para el estudio de los monumentos esculpidos de Chinkultic, Chiapas, Instituto de Investigaciones Filológicas, Centro de Estudios Mayas, unam, México.

NORDENSKIÖLD, Erland

1924 "The Ethnography of South America Seen from Mojos in Bolivia", en Comparative Ethnographical Studies, vol. 3, Goteburgo.

Poch Noguer, José

s. f. La pequeña industria al alcance de todos, $2^{\mathrm{a}}$ edición, tomo II, Casa Editorial Bailly-Bailliere, Madrid.

RECINOS, Adrián

1947 Popol Vuh. Las antiguas historias del Quiché, Biblioteca Americana, Fondo de Cultura Económica, México.

RoBicseK, Francis; Donald M. HALES

1981 The Maya Book of the Dead. The Ceramic Codex. The Corpus of Codex Style Ceramics of the Late Classic Period, University of Virginia Art Museum, Charlottesville, Virginia.

RoDAs, N. Flavio

1929 "Musica regional", en La Revista Musical, año II, núm. 18, Tipografía Nacional, Guatemala.

Ruiz A., María Elena

1995 "La sobrevivencia de armas tradicionales nativas en la Colonia, en una prohibición de que los indígenas porten armas. 1791",VIII Simposio de Arqueología Guatemalteca (1994), Instituto de Antropología e Historia-Asociación Tikal, Guatemala.

SAPPER, Karl

1903 "Mittelamerikanische waffen im modernen Gebrauche", en Globus, Band 83, Braunschweig. 
SCHMIDT, P.

1913 "Kulturkreise und kulturschichten in Südamerika", en Zeitschrift für Ethnologie, Band 45, Berlín.

Sноок, Edwin M.

1946 "Blowguns in Guatemala", en Notes of Middle American Archaeology and Ethnology, núm. 67, Carnegie Institution of Washington, Division of Historical Research.

STOLL, Otto

1986 "Etnografía de Guatemala", en Seminario de Integración Social Guatemalteca, núm. 8, Editorial del Ministerio de Educación Pública, Guatemala.

Tedlock, Dennis y Barbara

1993 "A Mayan Reading of the Story of the Stars", en Archaeology, vol. 46, núm. 4, Archaeological Institute of America, Nueva York.

THOMPSON, J. Eric

1930 "Ethnology of the Mayas of Southern and Central British Honduras", en Anthropological Series, vol. 17, núm. 2, Field Museum of Natural History, Chicago.

VAILLANT, George C.

1930 "Excavations at Zacatenco", en Anthropological Papers of the American Museum of Natural History, vol. 32, part I, lám. 39, Nueva York.

1931 "Excavations at Ticoman", en Anthropological Papers of the American Museum of National History, vol. 32, part 2, lám. 81, Nueva York.

VELA, David

1962 La marimba, estudio sobre el instrumento nacional, Biblioteca Guatemalteca de Cultura Popular, vol. 54, Ministerio de Educación Pública, Guatemala. 